\title{
Techniques of radioautography for medical and biological research
}

T. Nagata

\section{Correspondence \\ T. Nagata \\ Department of Anatomy and \\ Cell Biology \\ Shinshu University School of \\ Medicine \\ Matsumoto 390 \\ Japan \\ Fax: +81-263-33-6458}

Presented at the 5th International Symposium on Radioautography, São Paulo, SP, Brasil, August 24-26, 1997.

Received September 5, 1997 Accepted September 29, 1997
Department of Anatomy and Cell Biology,

Shinshu University School of Medicine, Matsumoto, Japan

Abstract

Standard techniques for radioautography used in biological and medical research can be classified into three categories, i.e., macroscopic radioautography, light microscopic radioautography and electron microscopic radioautography. The routine techniques used in these three procedures are described. With regard to macroscopic radioautography, whole body radioautography is a standard technique which employs freezing and cryosectioning and can demonstrate organ distributions of both soluble and insoluble compounds. In contrast, in light and electron microscopic radioautography, soluble and insoluble techniques are separated. In order to demonstrate insoluble labeled compounds, conventional chemical fixations such as formalin for light microscopy or buffered glutaraldehyde and osmium tetroxide for both light and electron microscopy followed by dehydration, embedding and wet-mounting applications of radioautographic emulsions can be used. For the demonstration of soluble labeled compounds, however, cryotechniques such as cryofixation, cryosectioning, freezedrying, freeze-substitution followed by dry-sectioning and dry-mounting radioautography should be employed both for light and electron microscopy. The outlines of these techniques, which should be utilized in various fields of biological and medical research, are described in detail.

\section{Principles of radioautography}

Radioautography (RAG) is the technique used to demonstrate the pattern of localization of various compounds labeled with radioactive isotopes (RI) in specimens (1). The specimens studied in natural sciences include animals, plants and minerals. In biological and medical research, however, the specimens are usually cells and tissues which contain radioactive substances. They are fixed, sectioned and placed in contact with the radioautographic emulsions, which are exposed and developed to produce metallic
Key words

- Macroscopic radioautography

- Light microscopic radioautography

- Electron microscopic radioautography

- Methodology silver grains for visualization. Such specimens are designated radioautographs and the patterns formed by silver grains are named radioautograms. Other terms such as autoradiography, autoradiographs and autoradiograms are sometimes used alternatively (2).

Since radioautograms are used for a variety of specimens, i.e., human biopsy material, experimental animal tissues and cells, plant tissues and cells or even whole bodies of small animals, the size of the specimens varies according to the samples used. Larger specimens such as whole bodies or large organs are designated macro-radioautograms 
Figure 1 - Diagrams showing the procedures for whole body radioautography. A, A frozen animal is fixed on the microtome stage and sectioned longitudinally and adhesive tape is attached to the section. $B$, After the cryosection is dried, the section is placed in contact with an $X$-ray film or tritium film (Kodak) in the darkroom and exposed. $C$, After exposure, the film and the section are separated and the film is developed.

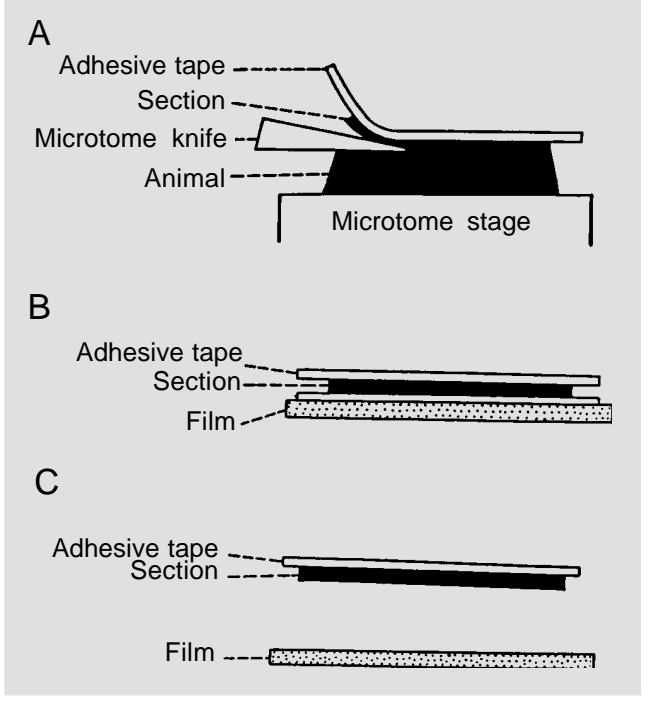

which are observed with the naked eye. Macroscopic radioautography (MRAG) can be classified into two levels, whole-body radioautography and organ radioautography. In contrast, small samples such as small pieces of tissues or cells are observed under the light (LM) or electron (EM) microscope, and the procedure is denoted microscopic radioautography and is classified into light microscopic radioautography (LMRAG) and electron microscopic radioautography (EMRAG). In addition, they are divided into two categories, soluble compound radioautography and insoluble compound radioautography from the viewpoint of solubility of the radioactive compounds (3). Thus, all radioautographs can be classified into 8 categories.

In general, macroscopic radioautography employs freezing, cryosectioning, freeze-drying and application of films, which demonstrate both soluble and insoluble compounds, and was first developed by Ullberg (4) to demonstrate the localization of penicillin. In contrast, light and electron microscopic radioautography usually employs chemical fixation and application of wet emulsions which demonstrate only insoluble compounds. This paper deals with standard techniques which can be used for biological and medical research.

\section{Macroscopic radioautography}

Macroscopic radioautography is a technique developed by Ullberg $(4,5)$ to demonstrate the localization of penicillin in the rat body and has been widely used to survey the incorporation of RI-labeled drugs in all major organs and tissues. It has been the basis for evaluating the distribution of new drugs in pharmacological research when new drugs are developed. The technique is simpler than microscopic radioautography.

Small animals such as mice and rats which received injections of RI-labeled drugs are frozen in a block of carboxymethylcellulose (CMC) gel. The whole-body cryosections (around $20-30 \mu \mathrm{m}$ ) are cut at $-20^{\circ} \mathrm{C}$ sagittally through the animal using a heavy sledge cryomicrotome such as LKB2250 (LKB, Bromma, Sweden). The cryosections are transferred to adhesive tape (Scotch tape), freeze-dried in a cryostat at $-20^{\circ} \mathrm{C}$ and attached to X-ray films or tritium films for exposure. After an adequate exposure time, the films and the sections are separated and the films are developed. For staining of sections or extraction of soluble compounds from sections, it is better to use soft Japanese paper between the sections and the adhesive tape (6). Routine techniques for MRAG are summarized below and in Figure 1.

1) Place the anesthetized animal on the cryomicrotome stage and pack CMC gel around it.

2) Immerse the stage and animal into hexane cooled with dry ice $\left(-70^{\circ} \mathrm{C}\right)$. It may take about 20-30 min to freeze the whole body. Alternatively, the animals can be quickly frozen in liquid nitrogen $\left(-169^{\circ} \mathrm{C}\right)$ and mounted into a viscous mixture of $6 \%$ (w/v) CMC.

3) Place the frozen animal and stage on the cryomicrotome and allow to equilibrate with the temperature of the cryostat around $-20^{\circ} \mathrm{C}$.

4) Cut the body longitudinally until the plane of the sectioning reaches those organs 
of interest. Then, stick a wide strip of transparent adhesive tape (3M, Minnesota Mining, MN, or any other) to the surface of the block. For the purpose of further staining or extraction, Japanese paper can be used (6). Insert a strip of soft Japanese paper made of mulberry paper between the frozen block and the adhesive tape before sectioning.

5) Cut a cryosection $(20 \mu \mathrm{m})$ for whole body radioautography slowly and steadily, attaching the tape to the section (Figure 1A).

6) Attach the cryosection with adhesive tape to a frame made of wire or plastic and freeze-dry at $-20^{\circ} \mathrm{C}$ overnight. When Japanese paper is used, press the section with paper and tape onto a glass slide coated with an egg-albumin and glycerine mixture. After drying, soak the section in water or solvent for extraction, if necessary.

7) Place the dry section in contact with $\mathrm{X}$-ray film or tritium film (Kodak) in the darkroom and store in a refrigerator for exposure (Figure 1B).

8) Separate the film and the section after exposure (Figure 1C) and develop the film with a recommended developer. Stain the section with either H-E or any other stain.

The above standard technique can be modified in various ways for particular purposes. To study glucose metabolism, for example, some freeze-dried sections on glass slides transferred using Japanese paper can be washed in cold $6 \%$ perchloric acid for extraction before and after radioautography to compare the soluble compounds (6).

\section{Light microscopic radioautography}

As standard techniques for LMRAG, tissues are fixed in chemical fixatives such as $10 \%$ formalin for LM only or phosphate buffered $2.5 \%$ glutaraldehyde and $1 \%$ osmium tetroxide for both LM and EM, followed by dehydration and embedding in either paraffin or epoxy resin. After sectioning, thick paraffin sections $(3-5 \mu \mathrm{m})$ or semithin Epon sections (1-2 $\mu \mathrm{m})$ are picked

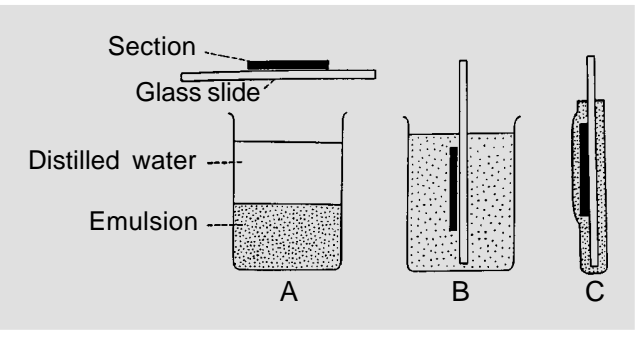

up on glass slides using water for expansion. Radioautographic emulsion can be placed over the sections by the stripping film or dipping method (Figure 2). Initially, after diluting bulk emulsion with distilled water (Figure 2A), we dip glass slides one by one (Figure 2B) and let them dry (Figure 2C). It takes much time to complete many slides. Then, many slide holders, each holding 15 slides, are dipped into meltedemulsion, dried, exposed, developed and stained simultaneously (7). In order to produce many radioautograms at once and also to compare them quantitatively under the same conditions, the following procedures are recommended (8).

1) Prepare glass slides, each carrying several paraffin sections or Epon semithin sections. Hold 15 glass slides in a stainless steel slide holder (Figure 3A), or any other similar type. Deparaffinize paraffin sections.

2) Melt a bottle of bulk emulsion (Konica NR-M2 emulsion, Konica Ltd., Tokyo, Japan) in a water bath at $45^{\circ} \mathrm{C}$ for about $10 \mathrm{~min}$. Add an equal amount of distilled water and mix with a glass slide to remove all air bubbles.

3) Dip the slide holder into the melted emulsion for several seconds, then pull it up vertically for about $3 \mathrm{~s}$ to assure a coating of equal thickness $(3-4 \mu \mathrm{m})$ over the sections (Figure 3B).

4) Wipe the bottom of the slide holder with a paper towel to remove excess emulsion (Figure 3C) and place the slide holder in an electric incubator at $28^{\circ} \mathrm{C}$ with $80 \%$ humidity, containing a wet sponge at the bottom. Dry them for $1 \mathrm{~h}$ in the incubator.

5) Store the slides in a light-tight slide
Figure 2 - Diagrams showing the procedures of the dipping method for LMRAG. A, After mounting sections on glass slides, bulk emulsion is melted and diluted with distilled water. $B$, The glass slides are dipped into the melted emulsion one by one. $C$, The dipped glass slides are pulled up and dried, exposed and developed. 
box containing a desiccant (silica gel). Seal the box with black tape and keep in a refrigerator at $4^{\circ} \mathrm{C}$ for exposure (Figure 3D).

6) Develop some glass slides for testing after 2-4-week exposure, placing them in a staining jar containing developer. When the exposure time is adequate, develop all the slides at once. If the exposure time is not enough, wait for another 2-4 weeks for more exposure. We use Konica KD-X1 developer for Konica NR-M2 emulsion. Kodak D-19 may be used for any type of emulsion. The recipes are listed in Table 1. Dissolve the gradients according to the order of this list. Otherwise, precipitation will occur.

7) Develop all the slides at once by pouring the developer into the slide box (Figure $3 \mathrm{E})$ after an adequate exposure time.

8) Rinse the slides in a stop bath (2\% aqueous acetic acid solution), fix in a fixer for 3 min twice, wash gently in running tap water for $10 \mathrm{~min}$, and dry.

9) Stain Epon sections in 1\% toluidine blue solution for light microscopy and paraffin sections with hematoxylin and eosin.

\section{Electron microscopic radioautography}

As standard techniques for EMRAG, ultrathin 100-nm sections should be used in general and examined with a conventional transmission electron microscope with the accelerating voltage at $100 \mathrm{kV}$. If any intermediate high voltage electron microscope is available, high accelerating voltages such as 200,300 or $400 \mathrm{kV}$, and thicker 200- or 300 $\mathrm{nm}$ sections can be used. We prefer to use semithin 200-nm sections in order to shorten the exposure time. Semithin sections are cut

\begin{tabular}{|c|c|c|}
\hline Reagent & Kodak D-19 & Konica KD-X1 \\
\hline Methol & $0.20 \mathrm{~g}$ & $0.35 \mathrm{~g}$ \\
\hline $\begin{array}{l}\text { Anhydrous } \\
\text { sodium sulfite }\end{array}$ & $9.00 \mathrm{~g}$ & $6.00 \mathrm{~g}$ \\
\hline Hydroquinone & $0.80 \mathrm{~g}$ & $0.90 \mathrm{~g}$ \\
\hline $\begin{array}{l}\text { Anhydrous } \\
\text { sodium carbonate }\end{array}$ & $5.25 \mathrm{~g}$ & $5.30 \mathrm{~g}$ \\
\hline Potassium bromide & $0.50 \mathrm{~g}$ & $0.25 \mathrm{~g}$ \\
\hline Distilled water & $100.00 \mathrm{ml}$ & $100.00 \mathrm{ml}$ \\
\hline
\end{tabular}
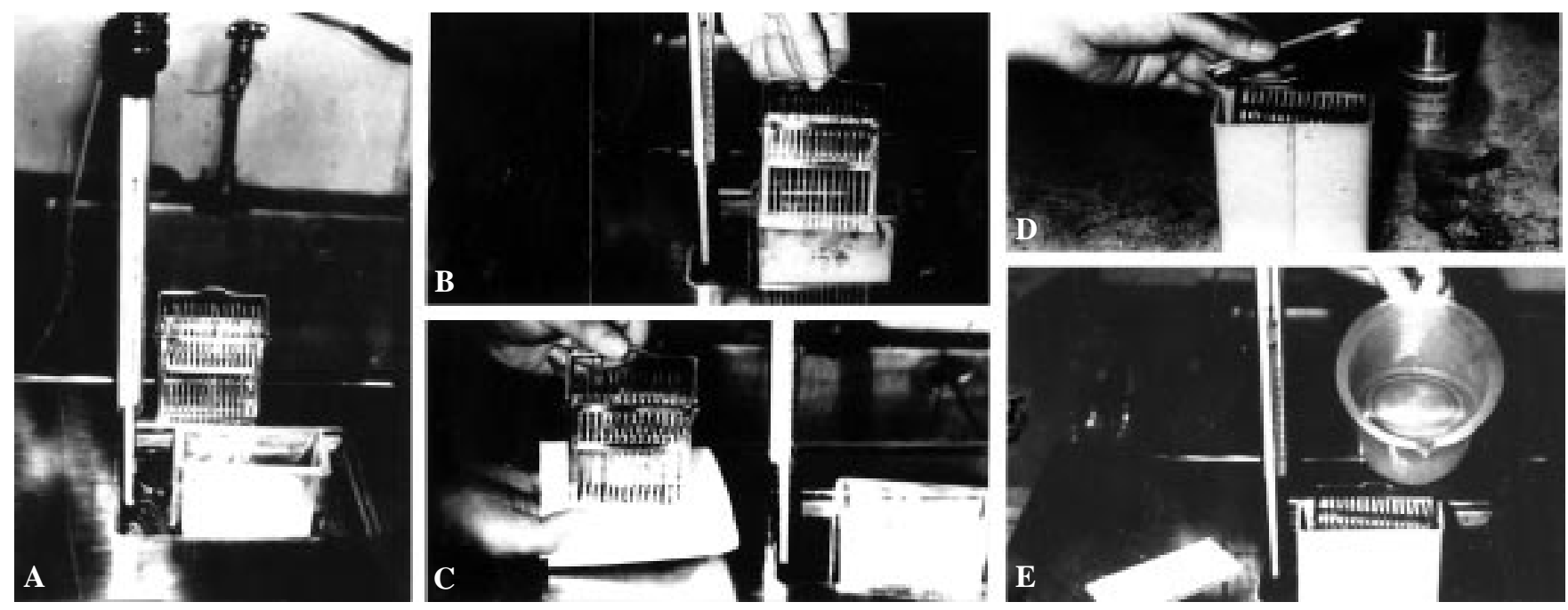

Figure 3 - Photographs showing the standard procedure for preparing LMRAG by the dipping method. A, Fifteen glass slides carrying sections are placed on a stainless steel slide holder, while bulk emulsion is melted and diluted with distilled water in a staining jar. $B$, The slide holder is dipped into the melted emulsion and pulled up vertically. $C$, Excess emulsion is wiped off with paper towels or tissue paper. $D$, The slide holder is stored in a lighttight slide box for exposure. E, After an appropriate exposure time, the developer is poured into the slide box and all the slides are developed at once. 
on a Porter-Blum MT-2B ultramicrotome. Ultramicrotomes of the mechanical feeding type are preferable to the thermal feeding type because of the accuracy of the section thickness, which affects the number of silver grains after radioautography. To obtain thin monolayers of silver bromide crystals, two techniques, dipping and the wire-loop method (Figure 4), are now in general use. We prefer the wire-loop method which was developed in our laboratory (9). The routine procedure in our laboratory is as follows (9-11).

1) Prepare a regular square glass block with $1.25-\mathrm{cm}$ sides from a glass strip No. 4890-40 for the LKB knife maker (LKBProdukter AB, Bromma, Sweden). Stick a square piece of double-coated Scotch tape, 4 $\mathrm{mm}$ in length, to the surface of each glass block. Place six grids around the tape like a rosette, arranged clockwise to identify each grid (Figure 5A). Coat the grids with a 10$\mathrm{nm}$ thick carbon layer under vacuum.

2) Dilute the radioautographic emulsion with an equal part of distilled water at $45^{\circ} \mathrm{C}$. We use Konica NR-H2 emulsion. Any other emulsion such as Kodak can alternatively be used. Add to $10 \mathrm{ml}$ of the diluted emulsion $0.2 \mathrm{ml} 2 \%$ aqueous solution of dioctyl sodium sulfosuccinate (a surfactant) in order to prevent the emulsion film from bursting (12).

3) Dip a platinum wire or vinyl-coated iron wire loop, $2.5 \mathrm{~cm}$ in diameter, into the diluted emulsion and pull out in order to obtain a thin film (Figure 5B).

4) Hold the wire loop horizontally in the air for $1 \mathrm{~min}$ and dry the emulsion.

5) Apply the emulsion film to the grids on the glass block horizontally like a quoit, while the emulsion film is gelled but still wet (Figure 5C).

6) Warm the glass block at $28^{\circ} \mathrm{C}$ for $1 \mathrm{~h}$ to dry the emulsion.

7) Check some of the emulsion films by electron microscopy before exposure to assure homogeneity of the film (Figure 5D).

8) Attach several glass blocks to one side of a microscopic slide with double-coated Scotch tape (Figure 5E).

9) Place several glass slides carrying several glass blocks in a black light-tight plastic slide box containing desiccant (silica gel), and seal the top with black tape (Figure 5F). Keep the slide box in a refrigerator at $4^{\circ} \mathrm{C}$ for exposure.

10) Soak the glass slides carrying glass blocks with grid meshes for development in a staining jar (Figure 5G), stop in a stop bath, fix in a fixer and stain with electron staining.

When a conventional MQ-developer such as D-19 is used, long spiral silver grains are formed. In order to obtain smaller silver grains, Elon-ascorbic acid developer or phenidon developer after gold latensification (G-L) is recommended (Table 2). We prefer the following procedure (13).

1) Soak the glass slides carrying grid meshes in distilled water in a staining jar for $10 \mathrm{~s}$.

2) Soak in G-L solution (Table 2) in a water bath at $16^{\circ} \mathrm{C}$ for $30 \mathrm{~s}$.

3) Rinse in distilled water for $10 \mathrm{~s}$.

4) Develop in phenidon developer (Table 2 ) in a water bath at $16^{\circ} \mathrm{C}$ for $60 \mathrm{~s}$.

5) Stop the development by soaking the slides in stopper solution (2\% aqueous acetic acid solution) for $10 \mathrm{~s}$.

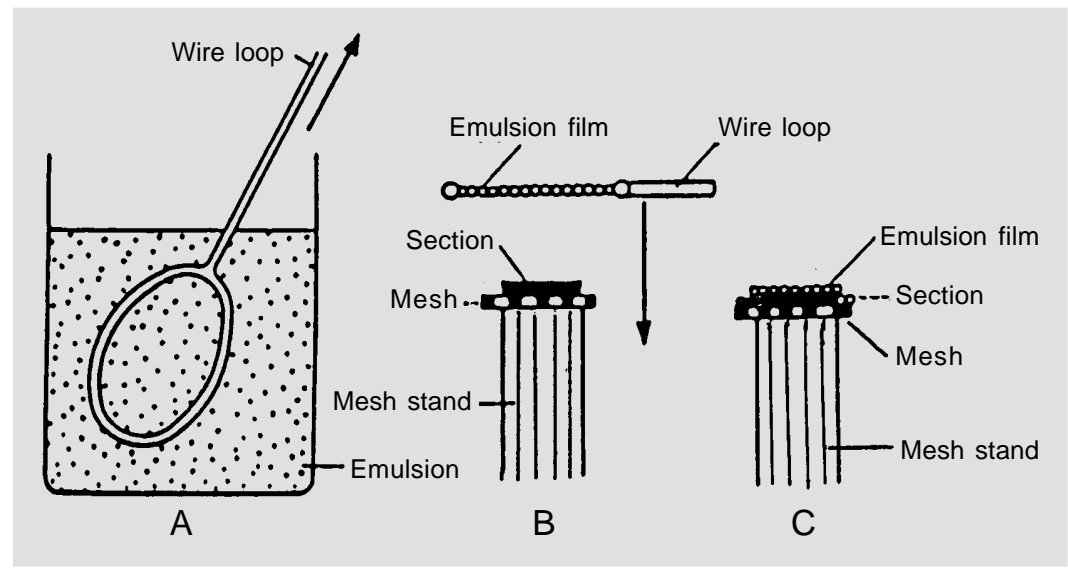

Figure 4 - Diagrams showing the procedures of the wire-loop method for EMRAG. A, A wire loop is dipped into melted and diluted emulsion and pulled up. $B$, A grid mesh carrying sections is placed on a mesh stand and sections are coated one by one with the emulsion film using a wire loop. $C$, The coated mesh is dried, exposed and developed. 
6) Fix in a fixer (30\% aqueous sodium thiosulfate solution) for 5 min with 2 changes.

7) Rinse in distilled water for $5 \mathrm{~min}$ with 3 changes.

8) Stain in lead citrate solution for $3 \mathrm{~min}$ and process with the stopper, fixer and several rinses in distilled water.

9) Stain the grids in a lead citrate solution for $3 \mathrm{~min}$ both for staining and removing the gelatin of the emulsion. We use a lead citrate solution consisting of $10 \mathrm{ml}$ distilled water and $30 \mathrm{mg}$ lead citrate, adjusted to $\mathrm{pH} 12$ with a few drops of $10 \mathrm{~N} \mathrm{NaOH}$ solution (9). The lead citrate solution proposed by Reynolds (14) can also be used. Uranyl staining is usually not necessary.

10) Rinse in distilled water for a few minutes.

11) Carefully remove the grids from the glass blocks with a forceps and place on filter paper in a Petri dish.

12) Dry in an incubator at $37^{\circ} \mathrm{C}$ for $1 \mathrm{~h}$.

13) Coat the grids with a 10 -nm thick carbon layer under vacuum.

Electron microscopy is carried out with

Table 2 - Fine grain developers for electron microscopy.

\begin{tabular}{lcc}
\hline Reagent & $\begin{array}{c}\text { Gold } \\
\text { latensification } \\
\text { solution }\end{array}$ & $\begin{array}{c}\text { Phenidon } \\
\text { developer }\end{array}$ \\
\hline $\begin{array}{l}2 \% \text { Gold chloride solution } \\
\text { Potassium thiocyanate }\end{array}$ & $0.20 \mathrm{ml}$ & \\
$\begin{array}{l}\text { Ascorbic acid } \\
\text { Phenidon }\end{array}$ & & $1.05 \mathrm{~g}$ \\
Potassium bromide & $0.06 \mathrm{~g}$ & $0.25 \mathrm{~g}$ \\
Potassium carbonate & & $0.60 \mathrm{~g}$ \\
Anhydrous sodium sulfite & & $1.30 \mathrm{~g}$ \\
Potassium thiocyanate & & $20.00 \mathrm{~g}$ \\
Distilled water & $100.00 \mathrm{ml}$ & $6.00 \mathrm{~g}$ \\
& &
\end{tabular}
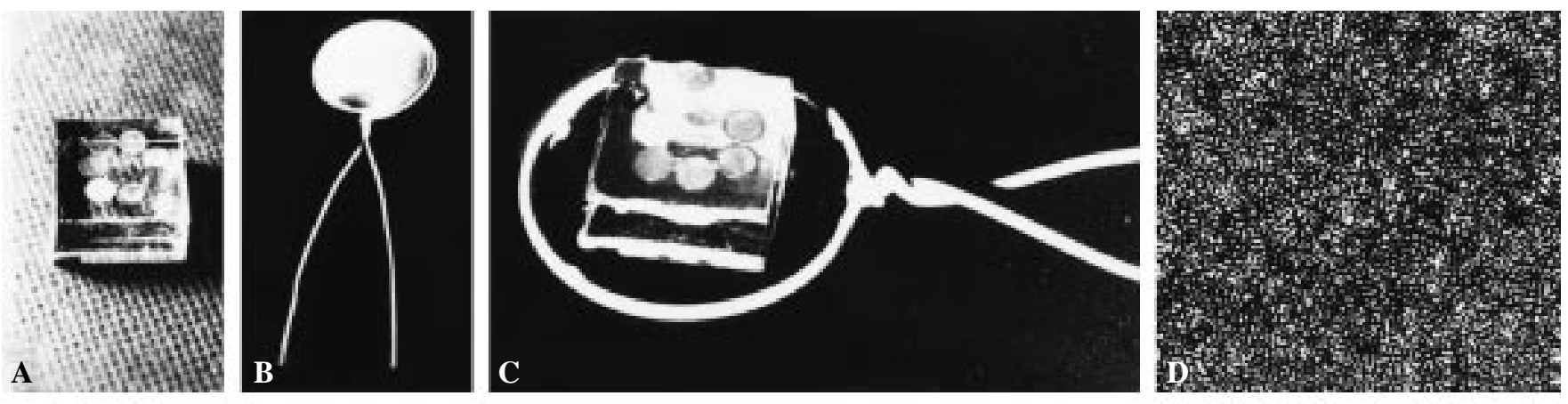
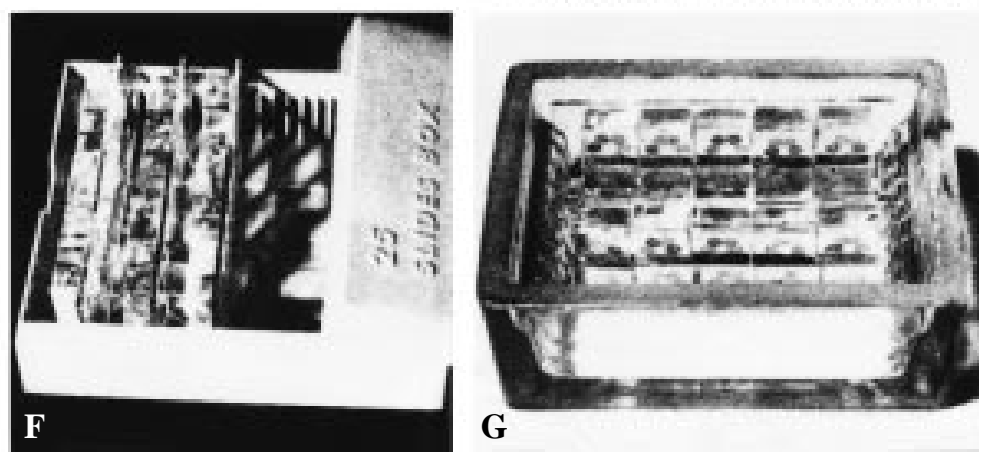

Figure 5 - Photographs showing the standard procedure for preparing EMRAG by the wire-loop method. A, Six meshes carrying sections are placed on a square glass block. $B$, A large wire loop is dipped into the melted emulsion and a thin film of emulsion is obtained. $C$, The emulsion film with the wire loop is applied horizontally to a glass block on which 6 meshes are placed. $D$, The emulsion film is checked by transmission electron microscopy before development. Note the monolayer arrangement of silver bromide crystals in Konica NR-H2 emulsion. X6,000. E, Ten glass blocks carrying 6 meshes each are attached to a glass slide with Scotch tape. F, Several glass slides, each carrying 10 glass blocks, are stored in a slide box for exposure. G, All the meshes on glass blocks are developed, fixed and stained simultaneously. 
electron microscopes equipped with accelerating voltages at 200,300 or $400 \mathrm{kV}$, when semithin sections are used to shorten the exposure time as well as to obtain better contrast for the observation of silver grains (9). We use either a Hitachi H-700 electron microscope at $200 \mathrm{kV}$ or a JEOL JEM4000EX electron microscope at 300 or 400 $\mathrm{kV}$.

\section{Microscopic dry-mounting radioautography for soluble compounds}

In order to demonstrate soluble labeled compounds at the light and electron microscopy levels, cryotechniques, including cryofixation, cryosectioning, freeze-drying, freeze-substitution followed by dry-sectioning and dry-mounting radioautography should be employed (15-17). When MRAG is used, cryofixation on dry ice, cryosectioning in a cryostat and dry-mounting with $\mathrm{X}$ ray films are the techniques routinely employed as described previously $(4,5)$. In contrast, in both light and electron microscopic radioautography, chemical fixation wet-sectioning and wet-mounting radioautography are the routine techniques, which demonstrate only insoluble compounds incorporated into macromolecules. In order to demonstrate soluble compounds at LM and EM levels, dry-mounting radioautography is necessary. The basic techniques for dry-mounting radioautography are summarized here.

For cryofixation, isopentane or propane as quenching fluid and liquid nitrogen $\left(-196^{\circ} \mathrm{C}\right)$ as cooling agent are commonly used. Instead of quenching fluids, a pure copper block is sometimes used in direct contact with the tissues. Cryoinstruments such as RF-2 (Eiko, Tokyo, Japan), JFDRFA (JEOL, Tokyo, Japan), cryoblock or cryovacublock (Reichert-Jung, Germany) are now commercially available.

Liquid nitrogen (200-300 ml) is carefully poured into a Dewer flask and a 50-ml beak- er is placed in the liquid nitrogen, then 20-30 $\mathrm{ml}$ of isopentane or propane is poured into the beaker. We prefer isopentane to propane. Within a few minutes the liquid isopentane begins to solidify at its melting point of $-160^{\circ} \mathrm{C}$ as it is cooled by the liquid nitrogen at $-196^{\circ} \mathrm{C}$. The tissue blocks or free cells adhering to a small piece of aluminum foil are plunged quickly into the isopentane with a pair of forceps. The frozen tissues are then removed from the isopentane, using a small cup made with a piece of aluminum foil $3 \mathrm{~cm}$ $x 3 \mathrm{~cm}$ in size, molded with a No. 00 gelatin capsule in order to prevent ice crystal formation, transferred to liquid nitrogen in a Dewer flask, and stored in liquid nitrogen until processing. In this process, if the tissues are exposed to the air, ice crystals will grow larger, and the fine structure will be damaged. The frozen tissues are then processed by cryosectioning, freeze-drying or freezesubstitution procedures. When the metal contact method is employed using cryoinstruments, we use JEOL JFD-RFA, and frozen tissues are removed from the copper blocks and stored in liquid nitrogen as well.

The frozen tissues can be directly cut by cryosectioning without any embedding. For light microscopic cryosectioning we use cryostats. For electron microscopic cryosectioning we use ultramicrotomes equipped with cryokits. For light microscopic cryosectioning, frozen tissues are cut in a cryostat at $-30^{\circ} \mathrm{C}$ and the frozen sections are placed on glass slides in contact with radioautographic emulsions for light microscopy. Various techniques are employed (18). Some scientists use a cryostat in a darkroom together with the radioautographic emulsions. We use the cryostat in a conventional bright room cutting cryosections which are then coated with the emulsion in a darkroom with a large wire loop (1). We use a conventional rotary type cryostat (Daimon, Olympus Opt. Co., Tokyo, Japan). The frozen tissues are transferred to a cryostat kept at about $-30^{\circ} \mathrm{C}$ and dry 20-30- $\mu \mathrm{m}$ sections are cut, transferred 
onto glass slides and either air-dried at room temperature or freeze-dried at $-30^{\circ} \mathrm{C}$ for a few hours. The procedure for coating the slides with dry emulsion film by the large wire-loop method will be described later.

For electron microscopic cryosectioning, we use LKB ultramicrotomes 4800 equipped with an LKB cryokit 14800 or LKB-NOVA (LKB, Bromma, Sweden). Another type of ultramicrotome such as DuPont-Sorvall or Reichert-Jung with cryokits can also be used. The temperature of the specimens is usually set from $-100^{\circ} \mathrm{C}$ to $-120^{\circ} \mathrm{C}$ and that of the glass knives at $-80^{\circ} \mathrm{C}$ to $-100^{\circ} \mathrm{C}$. The optimal temperature depends on the kind of tissues used. Dry sections are picked up with dry eyelash probes onto grids, covered with another grid as a sandwich and pressed with copper rods $(9,17)$. Grids used for this purpose are coated with collodion applied by soaking copper grids in $1 \%$ collodion solution and dried at $37^{\circ} \mathrm{C}$ for $1 \mathrm{~h}$. As controls, wet sections are picked up with sucrose droplets (18). Grids carrying dry sections are freeze-dried at $-50^{\circ} \mathrm{C}$ for $24 \mathrm{~h}$, using the same freeze-drying procedure as for the tissue blocks. Among the drying procedures tested, i.e., freeze-drying, freeze-substitution, and air-drying, the freeze-drying procedure was the best from the viewpoint of preservation of both cell structure and radioisotopes (12). In order to freeze-dry cryosections, we use a rotary cryotransfer apparatus (12). The rotary disc, which carries 5 grids with cryosections, is changed every 5 grids and transferred to a carrier which consists of a tube and a cylinder containing 5 discs in its shelves, for a total of 25 grids (12). The carrier is transferred to the desiccator of the freeze-drying apparatus, which is operated for $3 \mathrm{~h}$ at $-80^{\circ} \mathrm{C}$. After the cryosections are dried, they are coated with carbon and processed by the dry-mounting radioautographic procedure. Recently, cryotransfer apparatuses are commercially available as part of cryokit-equipped ultramicrotomes such as LKB, Sorvall or Reichert.
To freeze-dry the cryosections or frozen tissue blocks, we use a freeze-drying apparatus designed and constructed in our laboratory $(12,15)$. It consists of a cold trap, a desiccator, which is set in the cold trap, three Geisler, discharge and ionization vacuum gauges, and two rotary (RP) and oil diffusion (DP) vacuum pumps. The cold trap consists of a stainless steel cylinder containing liquid nitrogen. The desiccator, which is set in the cold trap, has 96 sets of thermoelements which can be controlled with electric current at temperatures between $-80^{\circ} \mathrm{C}$ and $+60^{\circ} \mathrm{C}$. The whole apparatus is capable of maintaining a pressure of less than $10^{-6}$ Torr. Similar freeze-drying apparatuses are now commercially available from several makers. The frozen tissues are transferred to the freezedrying apparatus using a ladle with a small aluminum cup. Freeze-drying should be carried out at first with the operation of the rotary pump for about an hour until the pressure reaches $10^{-3}$ Torr. The two pumps (RP and DP) are then operated for about 24 $\mathrm{h}$ to complete drying, while the desiccator is kept at $-80^{\circ} \mathrm{C}$. After the completion of freezedrying, the temperature is maintained over several hours by changing the electric current of the thermoelement, so that the whole drying procedure takes about $30 \mathrm{~h}$ in the case of tissue blocks. In the case of cryosections on grids, however, freeze-drying for only 12 $\mathrm{h}$ is enough. Before completion of the procedure, the epoxy embedding mixture is placed in the dripping unit which should be evacuated for 10 min by means of another rotary pump at a pressure of $10^{-3}$ Torr. After completion of drying, the embedding medium, either paraffin for LM or epoxy resin mixture for EM, is dripped down into the specimen chamber and the tissues are infiltrated and embedded. When fixation is preferable before embedding, in order to enhance contrast, freeze-dried tissues can be exposed to osmium vapor for $30 \mathrm{~min}$ in a tight jar containing a small piece of osmium tetroxide crystal. 
For freeze-substitution of frozen tissue blocks, we use a freeze-substitution instrument named CS-auto (Reichert-Jung) which can be controlled automatically. Before we purchased this apparatus, we used the following manual procedure:

1) Mix dry ice and acetone in a Dewer flask.

2) Put a small test tube or sample tube containing 20-30 $\mathrm{ml}$ of absolute acetone in the Dewer flask and cool to $-78^{\circ} \mathrm{C}$.

3) Transfer the frozen tissue blocks with aluminum foil cups to the test tube containing absolute acetone (15).

4) Keep the transferred tissues in the substituting fluid for $72 \mathrm{~h}$ to substitute the ice with the solvent. We use a deep freezer (Tabai, Tokyo, Japan) in which the Dewer flask is stored and the temperature is kept at $-80^{\circ} \mathrm{C}$.

5) Raise the temperature gradually to $20^{\circ} \mathrm{C}$ for several hours.

6) Transfer the tissues to an Epon/acetone mixture, then process and polymerize.

For dry sectioning of freeze-dried or freeze-substituted material, after freeze-drying or freeze-substitution the embedded tissues should be cut dry without using any water. We usually cut dry sections from epoxy resin-embedded tissues for both light and electron microscopy using ethylene glycol instead of water. We use glass slides or grids which are previously coated with collodion by dipping them into $1 \%$ collodion solution and drying them at $37^{\circ} \mathrm{C}$ for $1 \mathrm{~h}$. Both cryosectioned and freeze-dried specimens and freeze-dried or freeze-substituted and embedded specimens should be coated with dry radioautographic emulsions without using any water. The procedure is designated dry-mounting radioautography. Two procedures are used for dry-mounting radioautography, one for light microscopy and the other for electron microscopy procedures.

For the light microscopy dry-mounting procedure, several methods have been employed in the literature (18). However, those procedures are very complicated for the treatment of both specimens and emulsions. We use dry films produced with a large wire loop which is air-dried and applied to cryostat sections placed on glass slides (12). We believe that this method is the most convenient one. The procedure is as follows.

1) Pick up cryostat sections onto glass slides and dry. Dry epoxy resin sections are expanded over the slides with a drop of ethylene glycol without using any water.

2) Dilute the radioautographic emulsion with an equal part of distilled water at $45^{\circ} \mathrm{C}$. We use Konica NR-M2 emulsion (Tokyo, Japan). Any other emulsion such as Kodak can alternatively be used. Add to $10 \mathrm{ml}$ of diluted emulsion $0.2 \mathrm{ml} 2 \%$ aqueous solution of dioctyl sodium sulfosuccinate (a surfactant) in order to prevent the emulsion film from bursting (12).

3) Dip a large wire loop, $2.5 \mathrm{~cm}$ in diameter, which is made of platinum wire or vinyl-coated iron wire, and set with a piece of Scotch tape on a glass slide as a handle to obtain a thin film of emulsion.

4) Set the handle horizontally on a flat desk for air-drying.

5) Apply the film to the slide horizontally (Figure 6A) after air-drying for 1-2 min, when the center of the emulsion film is gelled and dried and transparent but the peripheral zone is still wet, appearing opaque.

6) Keep the glass slide on a Petri dish and warm at $28^{\circ} \mathrm{C}$ in an incubator for $1 \mathrm{~h}$ to dry the emulsion.

7) Place several glass slides in a black light-tight plastic slide box which contains desiccant (silica gel), and seal the top with black tape. Keep the slide in a refrigerator at $4^{\circ} \mathrm{C}$ for exposure.

8) Process the glass slides for development after an appropriate exposure time, then stop in a stop bath, fix in a fixer and stain with toluidine blue solution.

9) Control tissues should be fixed with chemical fixative, dehydrated, embedded, wet-sectioned and wet-mounted by conven- 
tional dipping procedures.

For the electron microscopic dry-mounting procedure, grids carrying dry sections (either freeze-dried or freeze-substituted Epon-embedded sections or freeze-sectioned and freeze-dried sections) are coated with a 5-10-nm thick carbon layer. They are placed on a grid holder made of a glass slide $(25 \mathrm{~mm}$ $\mathrm{x} 75 \mathrm{~mm}$ ) and 3 glass rods ( $3 \mathrm{~mm}$ in diameter and $10 \mathrm{~mm}$ in length) (Figure 6B). The routine procedures are as follows.

1) Dilute the radioautographic emulsion (Konica NR-H2) 1:10 with distilled water at $45^{\circ} \mathrm{C}$ in the darkroom.

2) Add to $10 \mathrm{ml}$ of the diluted emulsion $0.2 \mathrm{ml} 2 \%$ aqueous solution of dioctyl sodium sulfosuccinate at $45^{\circ} \mathrm{C}$ in a thermobath and mix for several minutes. Dioctyl sodium sulfosuccinate, a surface-activating agent, is used to prevent the emulsion films from bursting while they are being dried in the air $(12,16)$. We use Konica NR-H2 emulsion. Other emulsions for electron microscopic radioautography such as Kodak NOB or Alfred L4 can be used in a similar way.

3) Dip a small platinum wire loop, about 1 $\mathrm{cm}$ in diameter (Figure 6B), into the emulsion to obtain a thin film of the emulsion (16).

4) Set the handle of the wire loop on a flat surface for air-drying (for 1-2 min). The best condition for applying the film to the grid is in such a way that the peripheral zone of the film appears gelled but wet (opaque) while the central zone is gelled and almost dry, appearing transparent. The films are almost $100 \%$ air-dried without breaking by the use of a dioctyl sodium sulfosuccinate solution. Without this agent, all films will burst (12).

5) Apply the dry films to the grids on the holders like quoits (Figure 6B).

6) Transfer the grids to Petri dishes and warm at $37^{\circ} \mathrm{C}$ for $1 \mathrm{~h}$ to help the films adhere to the grids.

7) Keep the grids in a light-tight container with desiccant and sealed with black vinyl tape.

8) Store in a refrigerator at $4{ }^{\circ} \mathrm{C}$ for exposure.

9) Develop, stop and fix. We use gold latensification and phenidon developer. Other types of developer such as Kodak D-19 can also be used.

10) Rinse in distilled water, stain in lead citrate, and dry.

When several grids are attached to a square glass block, $12.5 \mathrm{~mm}$ in length (Figure 5A), a large wire loop, $2.5 \mathrm{~cm}$ in diameter, can be used as done for the wet-mounting procedure but after air-drying for a few minutes (Figure 5B,C). Several blocks are placed on a slide (Figure 5E), exposed, developed, fixed and stained simultaneously (Figure 5F,G).

As a control, radioautography by means


Figure 6 - Photographs showing the special procedure for preparing LMRAG and EMRAG by the dry-mounting method. $A, A$ large wire loop, $2.5 \mathrm{~cm}$ in diameter for LM, is dipped into the melted emulsion and air-dried for a few minutes and the dry film is applied to glass slides carrying sections. $B$, $A$ small wire loop, $1 \mathrm{~cm}$ in diameter for EM, is dipped into the melted emulsion and air-dried for a few minutes and the dry film is applied to the mesh on the grid holder. 
of conventional wet-mounting procedures for insoluble compounds should be carried out and compared with the dry-mounting.

\section{Conclusions}

The routine methods for macroscopic and microscopic radioautography to demonstrate both soluble and insoluble radioactive compounds were described in detail.

The methodologies are now well developed and should be applicable to any substance in any animal organ or tissue and cell for analyzing their localizations and functions in biological and medical research $(19,20)$.

\section{References}

1. Nagata $T$ (1992). Radiolabeling of soluble and insoluble compounds as demonstrated by light and electron microscopy. In: Wegmann RJ \& Wegmann MA (Editors), Recent Advances in Cellular and Molecular Biology. Vol. 6. Molecular Biology of Pyridines and DNA, Peroxisomes, Organelles and Cell Movements. Peeters Press, Leuven, Belgium, 9-21.

2. Nagata $T$ (1996). On the terminology of radioautography vs. autoradiography. Journal of Histochemistry and Cytochemistry, 44: 1209.

3. Nagata T (1982). Radioautography Data Book. I.P.C., Tokyo.

4. Ullberg S (1954). Studies on the distribution and fate of S35-labelled benzylpenicillin in the body. Acta Radiologica, 118: 1-110.

5. Ullberg S (1977). The techniques of whole body autoradiography. Cryosectioning of large specimens. Science Tools (Special issue): 195-199.

6. Shimada M \& Watanabe M (1995). Recent progress in whole-body radioautography. Cellular and Molecular Biology, 41: 39-48.
7. Nagata T, Shibata S \& Nawa T (1967). Simplified methods for mass production of radioautographs. Acta Anatomica Nipponica, 42: 162-166.

8. Nagata T (1982). Simple method for mass production of radioautographs. Cell (Saibo, in Japanese), 14: 40-50.

9. Nagata T (1996). Techniques and application of electron microscopic radioautography. Journal of Electron Microscopy, 45: 258-274.

10. Yoshida $K$, Murata $F$, Ohno $S$ \& Nagata $T$ (1978). A modified wire-loop method for quantitative electron microscopic radioautography. Histochemistry, 57: 93-96.

11. Nagata T (1995). Light and electron microscopic radioautographic studies on macromolecular synthesis in digestive organs of aging mice. Cellular and Molecular Biology, 41: 21-38.

12. Nagata $T \&$ Nawa $T$ (1966). A modification of dry-mounting technique for radioautography of water-soluble compounds. Histochemie, 7: 370-371.

13. Murata $F$, Yoshida $K$, Ohno $S$ \& Nagata $T$ (1979). Electron microscopic radioautography using a combination of phenidon developer and domestic emulsion. Acta Histochemica et Cytochemica, 12: 443450.
14. Reynolds ES (1963). The use of lead citrate at high $\mathrm{pH}$ as an electron opaque stain in electron microscopy. Journal of Cell Biology, 17: 208-212.

15. Nagata T (1994). Electron microscopic radioautography with cryo-fixation and dry mounting procedure. Acta Histochemica et Cytochemica, 27: 471-489.

16. Nagata T, Nawa T \& Yokota S (1969). A new technique for electron microscopic dry-mounting radioautography of soluble compounds. Histochemie, 18: 241-249.

17. Nagata T \& Murata F (1977). Electron microscopic dry-mounting radioautography for diffusible compounds by means of ultracryotomy. Histochemistry, 54: 75-82.

18. Nagata $T$, Ohno $S$, Yoshida $K$ \& Murata $F$ (1978). A simple picking up device for cryosections. Science Tools, 25: 59-60.

19. Nagata T (Editor) (1994). Radioautography in Medicine. Shinshu University Press, Matsumoto, Japan.

20. Wegmann R \& Nagata T (Editors) (1995). Radioautography: Special issue. Cellular and Molecular Biology, 41: 1-212. 